10.21611/qirt.2016.012

\title{
Non-destructive testing of works of art by stimulated by infrared thermography: PPT interest
}

\author{
By K. Mouhoubi ${ }^{*}$, J.L Bodnar*, V. Detalle ${ }^{* *}$, J.M. Vallet ${ }^{* * *}$
}

\begin{abstract}
* URCA / GRESPI / ECATHERM, UFR Sciences Exactes et Naturelles, BP 1039, 51687 Reims cedex 02, France, kmouhoubi@gmail.com, jl.bodnar@univ-reims.fr.

** LRMH, 29 avenue du Paris, 77420 Champs sur Marne, France, vincent.detalle@culture.gouv.fr.

*** CICRP, 21 rue Guibal, 13003 Marseille, France, jean-marc.vallet@cicrp.fr.
\end{abstract}

\section{Short abstract}

Within the framework of the cultural heritage conservation, stimulated infrared thermography has already demonstrated its efficiency. However, sometimes, the different colors of the paint layer can lead to artifacts of detection. In this work, we show theoretically and experimentally that the combination of a PPT analysis and of the stimulated infrared thermography allows a significant reduction of this disturbing optical effect.

\section{Introduction}

Within the framework of the conservation and the restoration of cultural heritage, a lot of laboratories are studying the possibilities of nondestructive testing using passive or stimulated Infrared thermography [1-53]. Among the research teams, we can cite the "Laboratoire de Recherche des Monuments Historiques " (LRMH), the "Centre interdisciplinaire de Conservation et Restauration du Patrimoine " (CICRP) and the "Groupe de Recherche en Sciences Pour l'Ingénieur »(GRESPI) of the Reims University. These three laboratories have worked together for over 10 years. This collaboration has already shown, using stimulated infrared thermography, the possibility to detect delamination located in heritage murals paintings (painted walls of the church of "Saint Florentin" in "Bonnet", painted ceilings of the Abbey of "Saint Savin sur Gartempe" - World Heritage of UNESCO ...) [39-54]. However, one of the problems encountered during this collaboration was the variable sensitivity of the pictorial layer according to the excitation flux. This difference in sensitivity can, in some worst cases, leads to artifacts of detection. In this work, we aim to reduce this disadvantage. With this objective, we have associated a PPT analyze (Pulse Phase Thermography [55-64]) to the stimulated infrared thermography. Indeed, we believe that this disruptive optical effect is rather of energy nature while those due to the presence of defects are also of temporal nature. Therefore, we believe that the phase images (with a temporal nature), resulting of a PPT post treatment, can reduce the optical disruptive effect. To test this hypothesis, we proceed in two steps: First we developed a series of theoretical simulations. Then we developed a series of experiments. This is the approach and the results obtained that we present here.

\section{Principle of frequency analysis used}

The frequency analysis method used for this study is a PPT (pulse phase thermography) analysis type. It consists first to briefly illuminate the artwork to analyze. It consists then to collect the photothermal signal emitted by the artwork. This first response already allows the detection of possible defects. But it is energy nature. Indeed the resulting photothermal signal is proportional to the temperature rise induced by the flash excitation. It is sensitive first to optical effects caused by the different colors of the paint layer of the studied artwork. It is sensitive then to an inhomogeneous energy deposit. This is precisely what is to be reduced. We cannot simply work with the first type of response. We have to add a post treatment leading the analyses of a parameter little sensitive to the deposited energy. Or the Fourier principle says that any mathematical function can be modeled by a sum of trigonometric functions (1)

$$
f(t)=\sum_{n=0}^{N} a_{n} \cos n \omega t+\sum_{n=0}^{N} b_{n} \sin n \omega t
$$




\subsection{1/qirt.2016.012}

This representation in the Fourier space, introduces for each frequency two characteristic parameters: the amplitude and phase of the analyzed function. This new representation of the photothermal signal presents two advantages. First, it gives access to two characteristic parameters which reduces detection artifacts. It permits then the access to the phase of the photothermal signal. This parameter measures the delay of the photothermal response compared to the excitation. It is then of temporal nature and not of energetic nature. It is then less sensitive to optical effects caused by the paint layer (with different colors) of the artwork studied. This explains its use in this work. The principle of the frequency analysis implemented in this study consist then, after flash analysis, to calculate the Fourier transform of the photothermal signal to obtain the harmonic response of the artwork studied (2).

$$
\mathrm{RH}(\mathrm{f})=\mathrm{TF}[\mathrm{RI}(\mathrm{t})]
$$

\section{Theoretical study}

To test our approach, we have developed a series of simulations. They use the finite element method to model the photothermal experience associated with the study. The analyzed sample (Figure 1) is a plaster block (because its thermo-physical properties are very close to those of a mural painting). Its geometric dimensions are the followings: the length is equal to $160 \mathrm{~mm}$. The width is equal to $120 \mathrm{~mm}$. The thickness is equal to $20 \mathrm{~mm}$. Its thermophysical properties are the followings: The thermal conductivity is equal to $0.4 \mathrm{~W} / \mathrm{m} \mathrm{K}$. The density is equal to $1100 \mathrm{~kg} / \mathrm{m}^{3}$. The heat capacity is equal to $830 \mathrm{~J} / \mathrm{kg} \mathrm{K}$. The thermal diffusivity is equal to $4.3810^{-7} \mathrm{~m}^{2} / \mathrm{s}$. In order to simulate the presence of delamination, we considered six air strip located in this sample. We considered that these defects were rectangular and had the same geometric dimensions. Length and width are equal to $20 \mathrm{~mm}$. Their thickness is equal to $4 \mathrm{~mm}$. Their depths vary from $2 \mathrm{~mm}$ to $12 \mathrm{~mm}$ by steps of $2 \mathrm{~mm}$ ( the sample scan is done from top to bottom and then from left to right). The thermophysical properties taken into account for these defects are those of the air, taken for a temperature equal to $20^{\circ} \mathrm{C}$. The thermal conductivity is equal to $0.026 \mathrm{~W} / \mathrm{m} \mathrm{K}$. The density is equal to $1.17 \mathrm{~kg} / \mathrm{m}^{3}$. The heat capacity is equal to $1006 \mathrm{~J} / \mathrm{kg} \mathrm{K}$. Finally, the thermal diffusivity is equal to $2.2210^{-5} \mathrm{~m}^{2} / \mathrm{s}$. Finally, to simulate the optical effects caused by the paint layer, we have on one hand, divided the surface of our sample into two parts. The first covers the defects located at 4 $\mathrm{mm}, 8 \mathrm{~mm}$ and $12 \mathrm{~mm}$ deep. The second covers defects located in $2 \mathrm{~mm}, 6 \mathrm{~mm}$ and $10 \mathrm{~mm}$ deep. We have imposed on the other hand an energetic flux 1.5 times more important on the second part relative to the first part. The excitation signal is a crenel. Its duration is equal to 2 seconds. The analysis duration is equal to 200 seconds. The acquisition frequency is equal to $1 \mathrm{Hertz}$. The deposited power is equal to $1500 \mathrm{~W}$. Finally we considered a model without thermal losses.

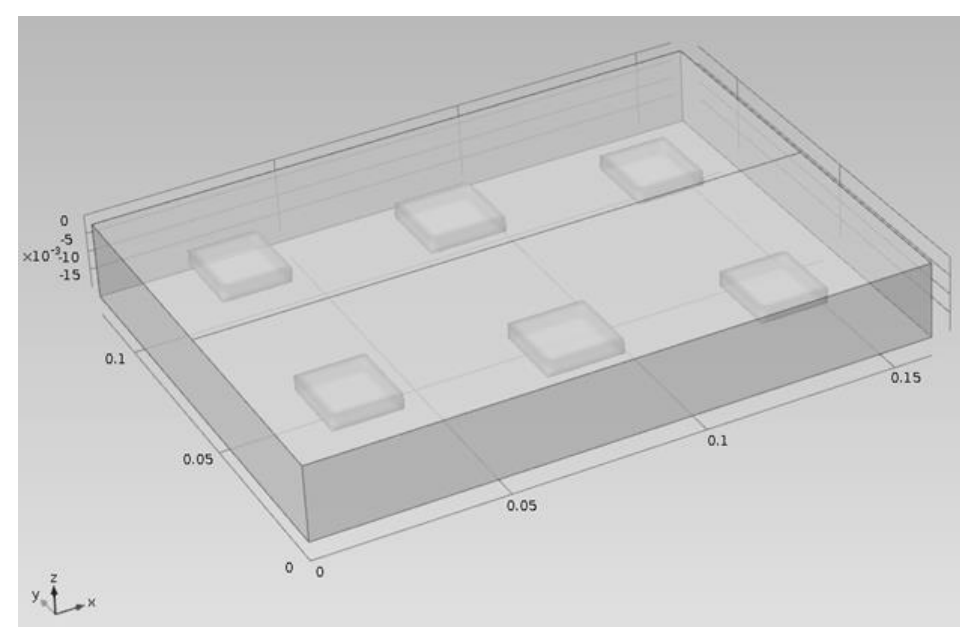

Fig.1. View of the sample theoretically studied

In figure 2, we present the thermograms obtained at $\mathrm{t}=28 \mathrm{~s}, \mathrm{t}=91 \mathrm{~s}, \mathrm{t}=177 \mathrm{~s}$ and $\mathrm{t}=200 \mathrm{~s}$. They show, as waited for a different photothermal signature at the place of the defects. They also show that these signatures are very disturbed by the energy deposition inhomogeneity. 


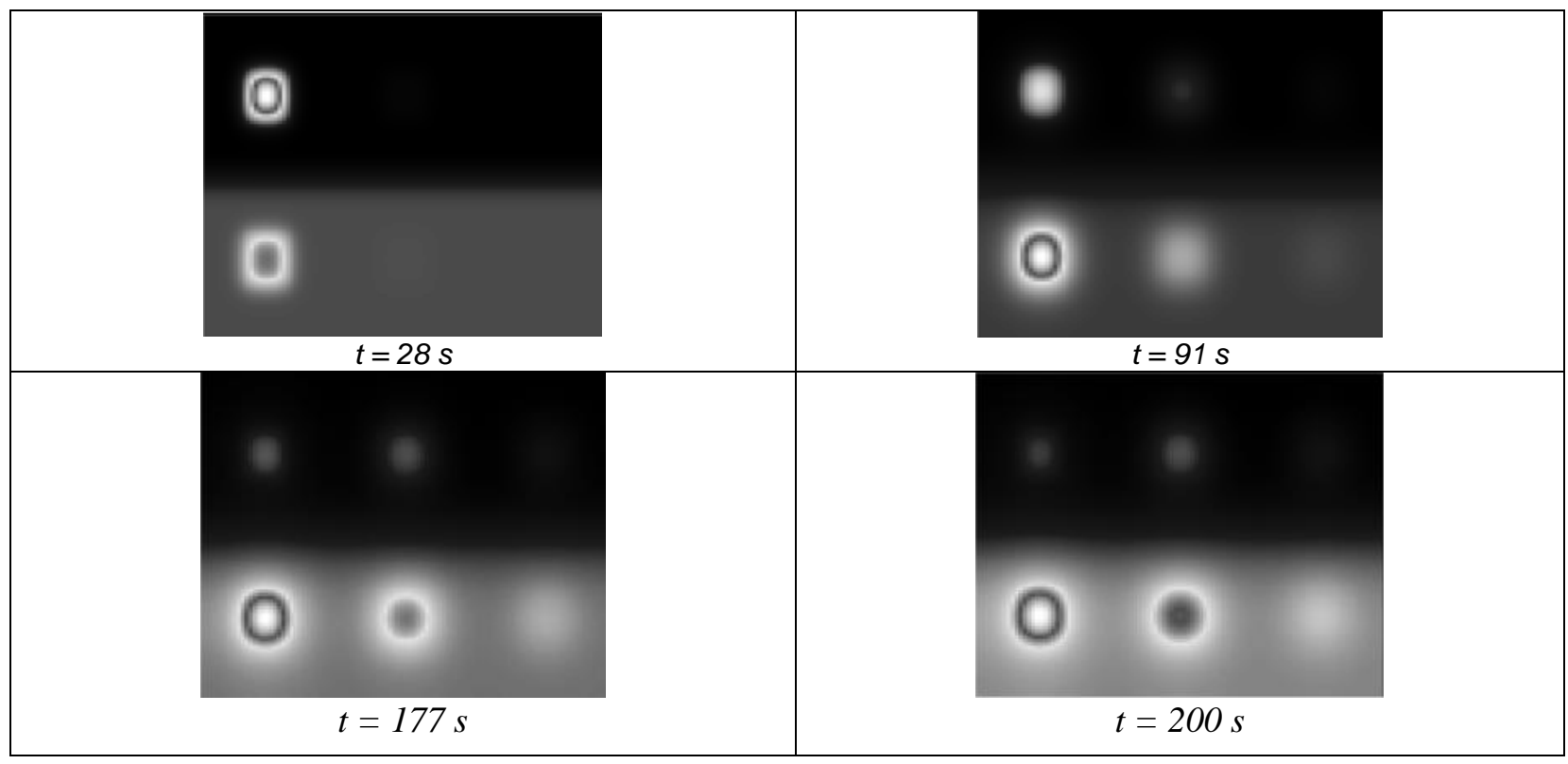

Fig.2. Example of theoretical thermograms obtained $(T=28 \mathrm{~s}, t=91 \mathrm{~s}, t=177 \mathrm{~s}$ and $t=200 \mathrm{~s})$

In figures 3 and 4 , we present then the results obtained after PPT frequency analysis type. Figure 3 represents the amplitude of the photothermal signal obtained. They respectively correspond to frequencies equal to $5 \mathrm{mHz}, 10 \mathrm{mHz}, 20 \mathrm{mHz}, 30 \mathrm{mHz}, 40 \mathrm{mHz}$ and $80 \mathrm{mHz}$ They show first that these signatures allow the defects detection. They show then that these signatures are still very sensitive to energy deposition inhomogeneity.

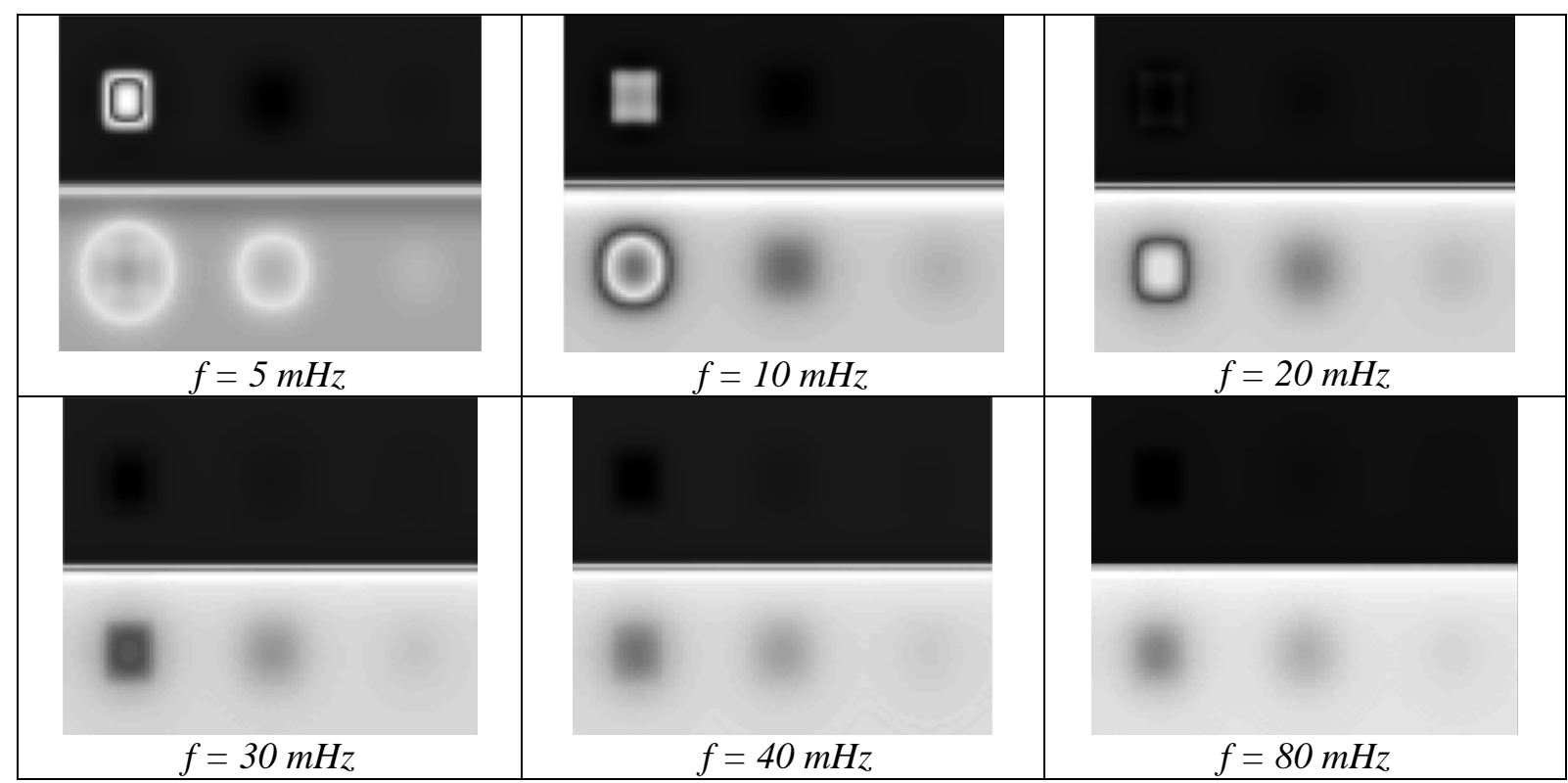

Fig.3. Amplitude images of the calculated harmonic response

Figure 4 shows, for the same frequencies, phase images obtained. They show on the one hand, the possibility to detect the six defects present in the studied sample. They show on the other hand, a good rejection of the optical effects caused by the paint layer. We can observe indeed, a homogenous photothermal signature in the healthy parts of the sample. The PPT frequency post treatment type seems then, theoretically, permits a better detection of defects located in a mural painting, via a partial rejection of optical effects caused by the paint layer. 


\subsection{1/qirt.2016.012}

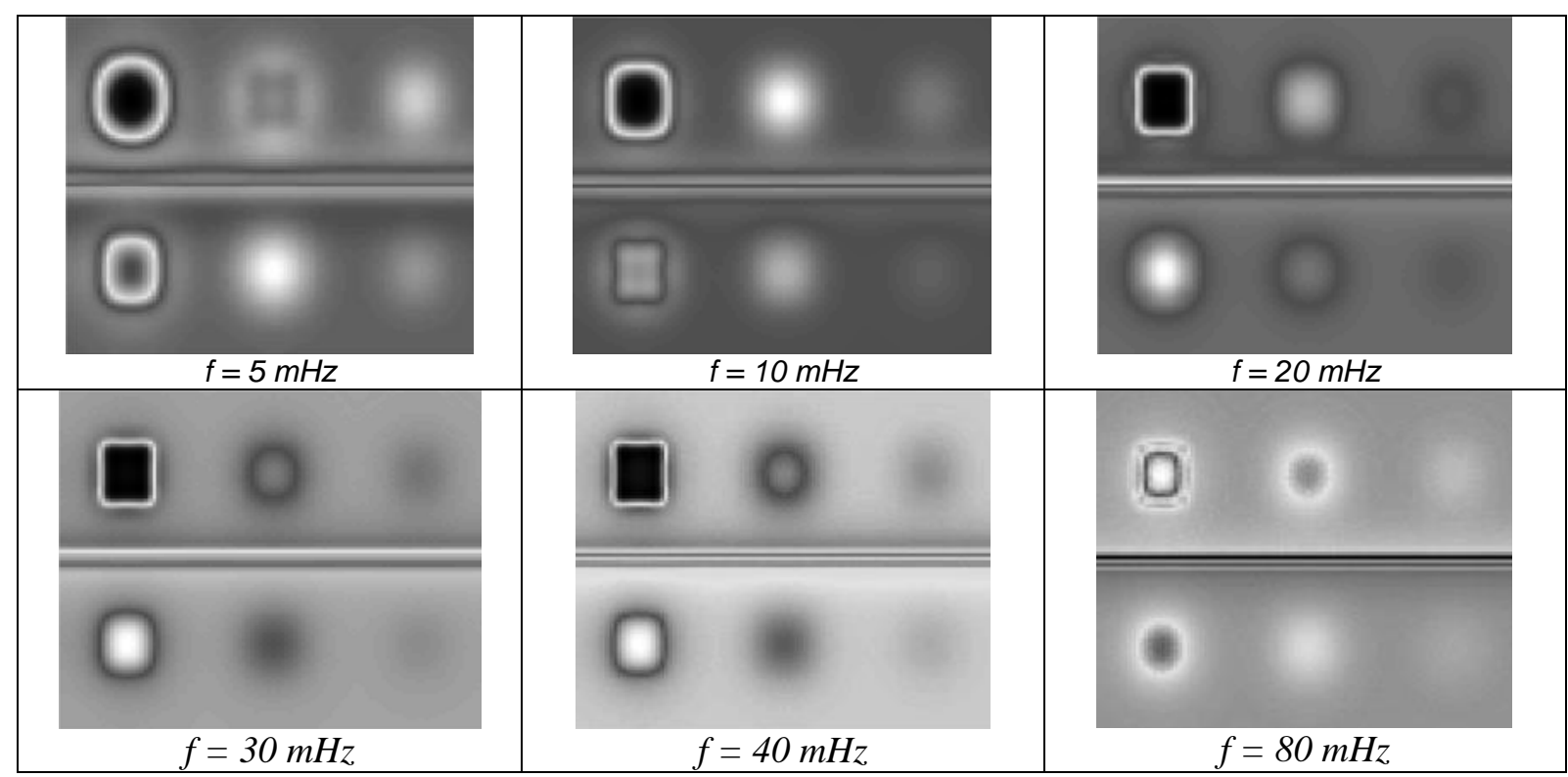

Fig.4. Phase images of the calculated harmonic response

\section{Experimental study}

Following this encouraging theoretical study, we switched on to an experimental study. The sample studied is presented in Figure 5. It is a plaster block. It is covered by a paint layer composed of 20 square parts with different colors. The colors chosen permit first to cover the visible spectrum (violet, green, blue, and yellow, orange, red). This choice permits then to study opposed radiative properties. Thus the black color permits to take into account a high absorptivity. The white color permits to take into account a high diffusion. Finally, the silver color allows taking into account a high reflectivity. Finally, these different colors permit a spatial inhomogeneity of energy absorption. The geometrical dimensions of this plaster block are the followings: The width is equal to 68 $\mathrm{cm}$. The height is equal to $50 \mathrm{~cm}$. the thickness is equal to $5 \mathrm{~cm}$. 32 Extruded polystyrene inserts were introduced into the sample. These are discs of $20 \mathrm{~mm}$ diameter and $2 \mathrm{~mm}$ thick. They were placed at a depth equal to $5 \mathrm{~mm}$. They were distributed so as to cover the entire surface of the studied sample.

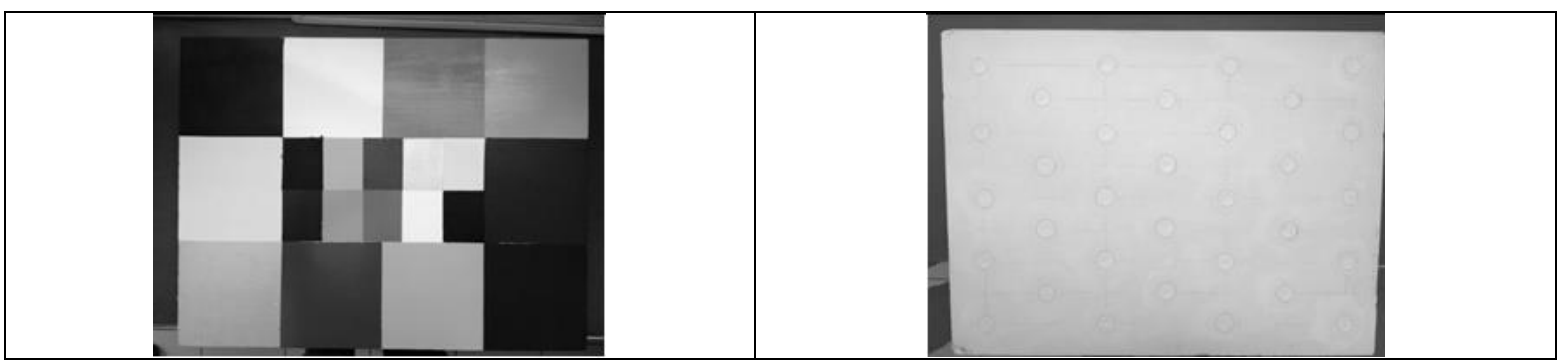

Fig.5. The analyzed sample

This sample was analyzed with the SAMMTHIR system of the laboratory. This has three main parts. First, it includes a couple of halogen lamps to excite the sample. Then, it include an infrared thermography camera SC655 type, to collect the photothermal signal. It includes still a data acquisition electronic. It includes finally a computer control. The experimental conditions used for the study are the followings: First the infrared thermography camera is located in front of the studied sample. The distance between the camera and the sample studied is equal to $150 \mathrm{~cm}$. The light sources are placed on either side of the camera. This geometrical configuration permits to light symmetrically and uniformly the studied sample. The excitation angle is equal to about 45 degrees. The distance sample existing between the sample and the light source is about equal to $60 \mathrm{~cm}$. The power of these lamps is equal to $500 \mathrm{~W}$. The excitation is a crenel type. The duration of the excitation is equal to 60 seconds. The duration of the analysis is equal to $194 \mathrm{~s}$. The acquisition frequency of the photothermal signal is equal to $1 \mathrm{~Hz}$. An example of result obtained is presented in Figure 6 . There are raw thermograms obtained at the instants $t=10 \mathrm{~s}, t=60 \mathrm{sec}$ and $t=120 \mathrm{~s}$. They clearly show the possibility to detect the majority of insulating inserts in the studied sample. They also show very clearly the important influence of the paint layer on the photothermal signal collected. 


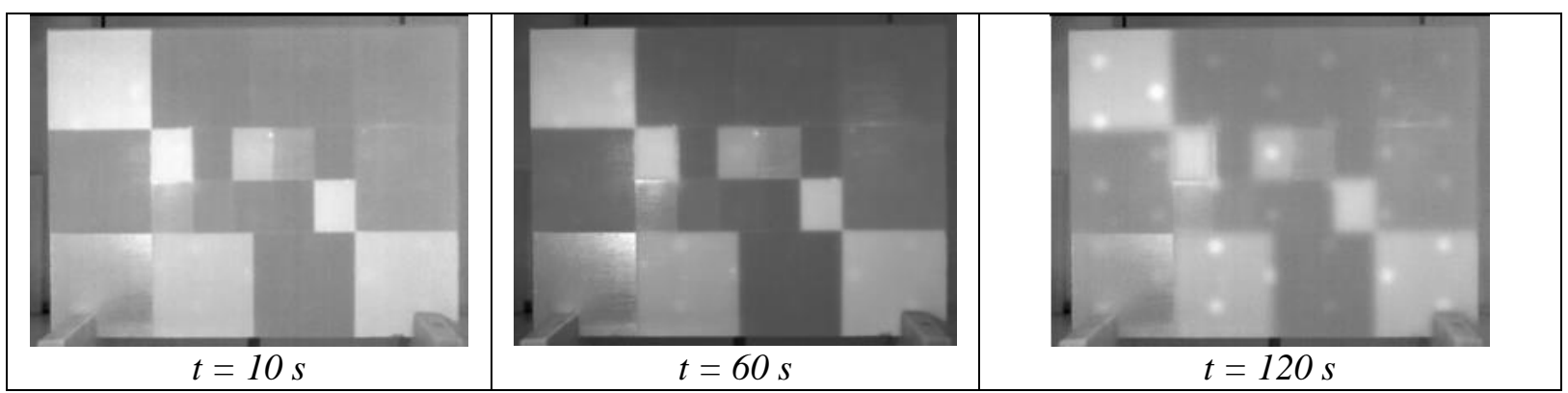

Fig.6. Example of raw experimental thermograms obtained (at $t=10 \mathrm{~s}, t=60 \mathrm{sec}$ and $t=120 \mathrm{~s}$ )

In figures 7 and 8, we present then the results obtained after PPT frequency analysis type. Figure 7 shows the amplitude pictures obtained. They correspond to the followings frequencies: $5.15 \mathrm{mHz}, 10.30 \mathrm{mHz}$ and $0.9 \mathrm{~Hz}$. They show as theoretically expected that these signatures allow first a partial detection of the defects located in the studied sample. They also show that they are still very sensitive to an inhomogeneity energy deposition.

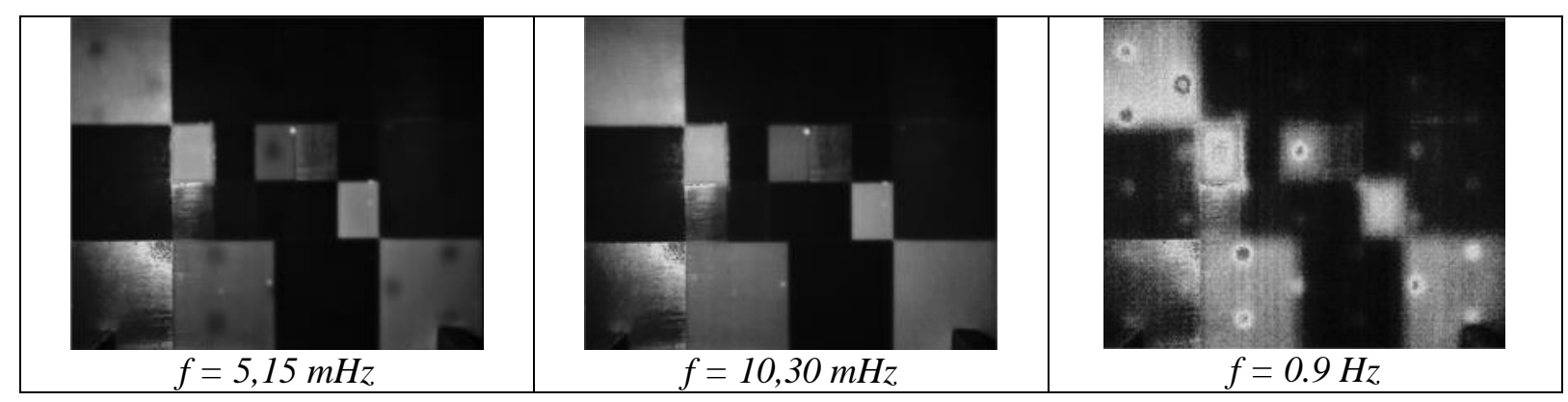

Fig.7. Amplitude pictures of the calculated harmonic response

Figure 8 shows, with the same frequencies, the phases pictures obtained. They show first the possibility to detect almost all the defects located in the test sample. They show then, a significant rejection of optical effects caused by the paint layer. It was the objective of this study.

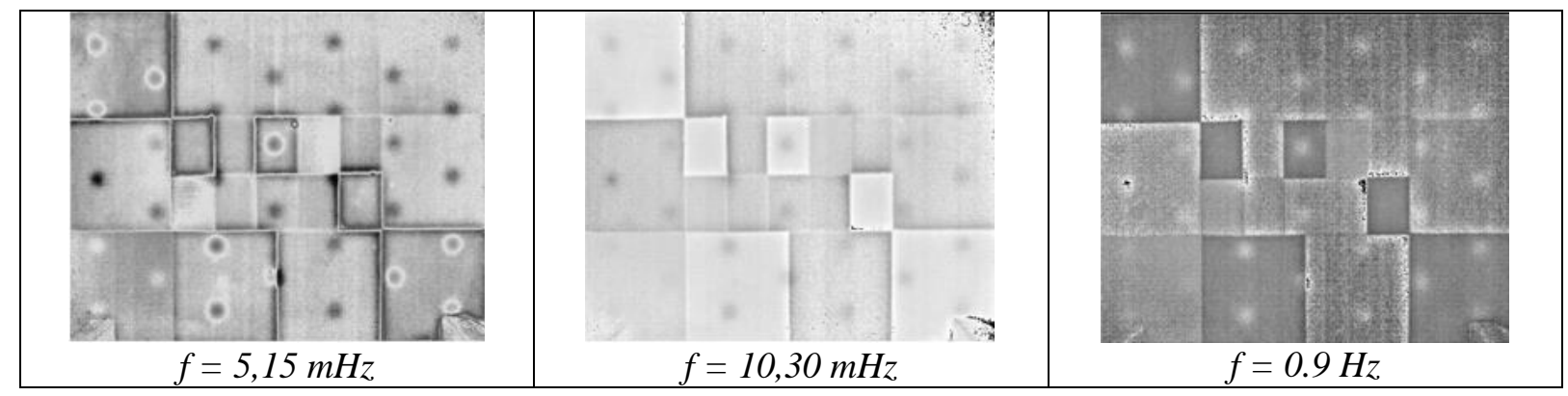

Fig.8. Phase pictures of the calculated harmonic response

\section{Conclusion}

In this work, we approached the possibilities of a PPT frequency analysis type associated with stimulated infrared thermography, to improve the restoration and conservation of works of art. We first noted that if the nondestructive testing of artworks by stimulated infrared thermography was already very powerful, it could be disrupted by the different colors of the paint layer. We then presented the principle of our approach. The latter considers that the disturbances caused by energy deposition inhomogeneity could be reduced by a temporal analysis of the collected photothermal signals. In our case, this temporal analysis is characterized by an analysis of the phase pictures of the harmonic response calculated by Fourier transform of the pulse response obtained by flash analysis. In order to confirm this hypothesis, we developed a theoretical study based on numerical modeling 


\subsection{1/qirt.2016.012}

of the photothermal experience using the finite element method. We showed first that the amplitude pictures allow a correct detection of defects, but they remain very sensitive to optical effects caused by the paint layer. We showed on the other hand, that the phase pictures allow a correct detection of the defects and also a significant reduction of the optical effects caused by the paint layer. Finally, we developed an experimental study to confirm the theoretical results. We then show during the study of a multicolored mural painting with the SAMMTHIR system of the laboratory, that the phase pictures allow an important rejection of optical effects induced by different colors the paint layer. These results are very encouraging. They seemed to allow the improvement the nondestructive testing of works of art by stimulated infrared thermography. They are now asking on one hand, to be generalized. They ask on another hand to be confirmed during in situ analysis. Studies going in this direction are in progress.

\section{REFERENCES}

[1] D. Ambrosini, C. Daffara, R. Di Biase, D. Paoletti, L. Pezzati, R. Bellucci, et F. Bettini, « Integrated reflectography and thermography for wooden paintings diagnostics », Journal of Cultural Heritage, vol. 11, no 2, p. 196-204, avr. 2010.

[2] N. Avdelidis et A. Moropoulou, "Applications of infrared thermography for the investigation of historic structures ", Journal of Cultural Heritage, vol. 5, no 1, p. 119-127, 2004.

[3] E. Barreira et V. P. de Freitas, "Evaluation of building materials using infrared thermography ", Construction and Building Materials, vol. 21, no 1, p. 218-224, 2007.

[4] P. Bison, A. Bortolin, G. Cadelano, G. Ferrarini, L. Finesso, F. Lopez, X. Maldague, C. S. U. ITC-CNR, et C. S. U. ISIB-CNR, «Evaluation of frescoes detachments by partial least square thermography ».

[5] P. Bison, A. Bortolin, G. Cadelano, G. Ferrarini, F. López, et X. Maldague, "Comparison of image processing techniques for the on-site evaluation of damaged frescoes ", in SPIE Sensing Technology+ Applications, 2014, p. 91050E-91050E.

[6] K. Blessley, C. Young, J. Nunn, J. Coddington, et S. Shepard, « The feasibility of flash thermography for the examination and conservation of works of art », Studies in Conservation, vol. 55, no 2, p. 107-120, 2010.

[7] B. Cannas, S. Carcangiu, G. Concu, et N. Trulli, « Modeling of Active Infrared Thermography for Defect Detection in Concrete Structures ».

[8] G. M. Carlomagno et C. Meola, "Comparison between thermographic techniques for frescoes NDT », NDT \& E International, vol. 35, no 8, p. 559-565, 2002.

[9] J.-P. Chambard et A. Roche, « Defect detection of wall paintings in the Chateau de Versailles using TVholography and IR thermography ", in Optical Metrology, 2007, p. 66180Y-66180Y.

[10] K. Chatterjee, S. Tuli, S. G. Pickering, et D. P. Almond, " A comparison of the pulsed, lock-in and frequency modulated thermography nondestructive evaluation techniques », NDT \& $E$ International, vol. 44, no 7, p. 655-667, nov. 2011.

[11] C. Daffara, L. Pezzati, D. Ambrosini, D. Paoletti, R. Di Biase, P. I. Mariotti, et C. Frosinini, « Wide-band IR imaging in the NIR-MIR-FIR regions for in situ analysis of frescoes », 2011, p. 808406-808406-12.

[12] G. Doni, N. Orazi, F. Mercuri, C. Cicero, U. Zammit, S. Paoloni, et M. Marinelli, « Thermographic study of the illuminations of a 15th century antiphonary », Journal of Cultural Heritage, vol. 15, no 6, p. 692-697, nov. 2014.

[13] T. Fricke-Begemann, G. Gülker, K. D. Hinsch, et H. Joost, « Remote localization of debonded areas in historical murals by TV-holography », Non-Destructive Testing and Microanalysis for the Diagnostics and Conservation of the Cultural and Environmental Heritage, Proceedings of art, vol. 99, p. 247-255.

[14] D. Gavrilov, R. G. Maev, et D. P. Almond, " A review of imaging methods in analysis of works of art: Thermographic imaging method in art analysis », Canadian Journal of Physics, vol. 92, no 4, p. 341-364, avr. 2014

[15] R. Gr et D. Gavrilov, « Thermography in Analysis of Works of Art: Choice of the Optimal Approach ».

[16] E. Grinzato, P. Bison, S. Marinetti, et V. Vavilov, « Nondestructive evaluation of delaminations in fresco plaster using transient infrared thermography », Res Nondestr Eval, vol. 5, no 4, p. 257-274, déc. 1994.

[17] E. Grinzato, P. G. Bison, et S. Marinetti, « Monitoring of ancient buildings by the thermal method », Journal of Cultural Heritage, vol. 3, no 1, p. 21-29, avr. 2002.

[18] E. Grinzato, «IR thermography applied to historical buildings », Proc. QIRT 02 (Dubrovnik), p. 3-14, 2002.

[19] E. Grinzato, P. G. Bison, C. Bressan, et A. Mazzoldi, « NDE of frescoes by infrared thermography and lateral heating », in Eurotherm Seminar, 1998, vol. 60, p. 64-67.

[20] K. Janssens, J. Dik, M. Cotte, et J. Susini, "Photon-based techniques for nondestructive subsurface analysis of painted cultural heritage artifacts », Accounts of chemical research, vol. 43, n० 6, p. 814-825, 2010.

[21] Y. H. Jo et C. H. Lee, «Quantitative modeling of blistering zones by active thermography for deterioration evaluation of stone monuments », Journal of Cultural Heritage, vol. 15, n 6, p. 621-627, nov. 2014. 


\subsection{1/qirt.2016.012}

[22] J. R. Kominsky et T. F. Martin, « Passive Infrared Thermography—A Qualitative Method for Detecting Moisture Anomalies in Building Envelopes ».

[23] F. López, S. Sfarra, C. Ibarra-Castanedo, D. Ambrosini, et X. P. V. Maldague, " Role of the masonry in paintings during a seismic event analyzed by infrared vision », présenté à Proceedings of SPIE - The International Society for Optical Engineering, 2015, vol. 9527.

[24] C. Meola, R. Di Maio, N. Roberti, et G. M. Carlomagno, « Application of infrared thermography and geophysical methods for defect detection in architectural structures », Engineering Failure Analysis, vol. 12, no 6, p. 875-892, déc. 2005.

[25] F. Mercuri, C. Cicero, N. Orazi, S. Paoloni, M. Marinelli, et U. Zammit, « Infrared Thermography Applied to the Study of Cultural Heritage », International Journal of Thermophysics, p. 1-6, 2014.

[26] F. Mercuri, U. Zammit, N. Orazi, S. Paoloni, M. Marinelli, et F. Scudieri, « Active infrared thermography applied to the investigation of art and historic artefacts ", Journal of thermal analysis and calorimetry, vol. 104, no 2, p. 475-485, 2011.

[27] B. F. Miller, "The feasibility of using thermography to detect subsurface voids in painted wooden panels », Journal of the American Institute for Conservation, vol. 16, no 2, p. 27-35, 1977.

[28] A. Moropoulou, N. P. Avdelidis, M. Koui, E. T. Delegou, et T. Tsiourva, "Infrared thermographic assessment of materials and techniques for the protection of cultural heritage ", in Multispectral Image Processing and Pattern Recognition, 2001, p. 313-318.

[29] A. Pelagotti, A. Mastio, A. Rosa, et A. Piva, "Multispectral imaging of paintings », IEEE Signal Processing Magazine, vol. 25, no 4, p. 27-36, juill. 2008.

[30] E. Rosina et E. C. Robison, « Applying infrared thermography to historic wood-framed buildings in North America », APT bulletin, vol. 33, no 4, p. 37-44, 2002.

[31] S. Sfarra, C. Ibarra-Castanedo, D. Ambrosini, D. Paoletti, A. Bendada, et X. Maldague, " Integrated approach between pulsed thermography, near-infrared reflectography and sandwich holography for wooden panel paintings advanced monitoring », Russ J Nondestruct Test, vol. 47, no 4, p. 284-293, avr. 2011.

[32] S. Sfarra, C. Ibarra-Castanedo, S. Ridolfi, G. Cerichelli, D. Ambrosini, D. Paoletti, et X. Maldague, « Holographic Interferometry (HI), Infrared Vision and X-Ray Fluorescence (XRF) spectroscopy for the assessment of painted wooden statues: a new integrated approach », Appl. Phys. A, vol. 115, no 3, p. 1041-1056, juin 2014.

[33] S. Sfarra, P. Theodorakeas, C. Ibarra-Castanedo, N. P. Avdelidis, A. Paoletti, D. Paoletti, K. Hrissagis, A. Bendada, M. Koui, et X. Maldague, «Importance of integrated results of different non-destructive techniques in order to evaluate defects in panel paintings: the contribution of infrared, optical and ultrasonic techniques ", 2011, vol. 8084, p. 80840R-80840R-13.

[34] S. Sfarra, C. Ibarra-Castanedo, D. Ambrosini, D. Paoletti, A. Bendada, et X. Maldague, "Defects detection and non-destructive testing (NDT) techniques in paintings: a unified approach through measurements of deformation », in SPIE Optical Metrology 2013, 2013, p. 87900G-87900G.

[35] G. S. Spagnolo, G. Guattari, E. Grinzato, P. G. Bison, D. Paoletti, et D. Ambrosini, " Frescoes diagnostics by electro-optic holography and infrared thermography ", in 6th World Conference on NDT and Microanalysis in Diagnostics and Conservation of Cultural and Environnemental Heritage, Rome, 1999 , p. 385-398.

[36] J. Spodek et E. Rosina, "Application of infrared thermography to historic building investigation ", Journal of Architectural Conservation, vol. 15, no 1, p. 65-81, 2009

[37] G. Szatanik : Etude et restauration d'une peinture murale représentant Saint Christophe (collection Campana, Louvre). Essai d'application de la thermographie infrarouge stimulée pour l'examen du support. INP, Sept 2004.

[38] P. Theodorakeas, S. Sfarra, C. Ibarra-Castanedo, N. P. Avdelidis, M. Koui, X. P. V. Maldague, D. Ambrosini, et D. Paoletti, "The use of Pulsed Thermography for the investigation of art and cultural heritage objects ".

[39] P. Theodorakeas, N. P. Avdelidis, E. Cheilakou, et M. Koui, « Quantitative analysis of plastered mosaics by means of active infrared thermography ", Construction and Building Materials, vol. 73, p. 417-425, 2014.

[40] V. Tornari, E. Bernikola, E. Tsiranidou, K. Hatzigiannakis, M. Andrianakis, V. Detalle, J.L Bodnar : Micromapping of defect structural micro-morphology in the documentation of fresco wallpaintings, International Journal of Heritage in the Digital Era, vol 2, $\mathrm{n}^{\circ} 1,2013, \mathrm{pp} 1-23$.

[41] P. Vázquez, C. Thomachot-Schneider, K. Mouhoubi, G. Fronteau, M. Gommeaux, D. Benavente, V. Barbin, J.L. Bodnar: Infrared Thermography monitoring of the $\mathrm{NaCl}$ crystallisation process, Infrared Physics \& Technology, 71, 2015, pp 198 - 207.

[42] J.L. Bodnar, J.L. Nicolas, J.C. Candoré, V. Detalle : đNon-destructive testing by infrared thermography under random excitation and ARMA analysis, International Journal of Thermophysics, 2012, vol 33, pp 2011-2015.

[43] J.L Bodnar, J. C Candoré, J.L. Nicolas, G. Szatanik, V. Detalle, J.M.Vallet : Stimulated infrared thermography applied to help for restoration of mural paintings, NDT/E International, 49, pp 4046, 2012

[44] J.L. Bodnar, K. Mouhoubi, G. Szatanik-Perrier, J.M. Vallet, V. Detalle : Photothermal thermography applied to the non-destructive testing of different types of works of art, International Journal of Thermophysics, ๆ2012, vol 33, pp 1996-2000. 


\subsection{1/qirt.2016.012}

[45] J.L Bodnar, J.L. Nicolas, K. Mouhoubi, V. Detalle : Stimulated infrared thermography applied to thermophysical characterization of cultural heritage mural paintings, European physical journal : Applied physics, 2012, 60, 21003.

[46] J. L. Bodnar, J. L. Nicolas, K. Mouhoubi, J. C. Candore, et V. Detalle, « Characterization of an Inclusion of Plastazote Located in an Academic Fresco by Photothermal Thermography », International journal of thermophysics, vol. 34, no 8-9, p. 1633-1637, 2013.

[47] J.L. Bodnar, K. Mouhoubi, L. Di Pallo, V. Detalle, J.M. Vallet, T. Duvaut : Contribution to the improvement of heritage mural painting non-destructive testing by stimulated infrared thermography, European physical journal : Applied physics, 2013, 64, 11001

[48] J.C. Candoré : Détection et caractérisation de défauts par thermographie infrarouge stimulée : Application au contrôle d'œuvres d'art. PhD, Reims, June 2010.

[49] J. C. Candoré, J. L. Bodnar, V. Detalle, et P. Grossel, « Non-destructive testing of works of art by stimulated infrared thermography », The European Physical Journal Applied Physics, vol. 57, n 02, p. 21002, 2012.

[50] J. C. Candoré, J.L Bodnar, V. Detalle, P. Grossel : Non destructive testing of work of art by stimulated infrared thermography. European physical journal Applied Physics, 2012, vol 57, 02, pp 21002 210011.

[51] J.C. Candoré, J.L Bodnar, V. Detalle, P. Grossel : Characterization of defects situated in a fresco by stimulated infrared thermography, European physical journal Applied $\quad$ Physics, 2012, vol 57, 01, pp $11002-11008$

[52] J.L Bodnar, J.L. Nicolas, K. Mouhoubi, V. Detalle : Stimulated infrared thermography applied to thermophysical characterization of cultural heritage mural paintings, February 2012, vol 57, issue 2.

[53] K. Mouhoubi, J.L Bodnar, J.L. Nicolas, V. Detalle, J.M. Vallet, T. Duvaut : Contribution to the local thermophysical characterization of murals paintings of the inheritance by stimulated infra-red thermography, proc of QIRT 2014, Bordeaux, 7-11 juillet 2014.

[54] X. Maldague et S. Marinetti, "Pulse phase infrared thermography », J. Appl. Phys., vol. 79, no 5, p. 2694-2698, 1996.

[55] X. Maldague, F. Galmiche, et A. Ziadi, "Advances in pulsed phase thermography », Infrared Phys. Technol., vol. 43, no 3, p. 175-181, 2002.

[56] X. Maldague, Y. Largouet, et J.-P. Couturier, «A study of defect depth using neural networks in pulsed phase thermography: modelling, noise, experiments ", Revue générale de thermique, vol. 37, no $8, p$. 704-717, 1998.

[57] R. W. Arndt, "Square pulse thermography in frequency domain as adaptation of pulsed phase thermography for qualitative and quantitative applications in cultural heritage and civil engineering ", Infrared Physics \& Technology, vol. 53, no 4, p. 246-253, juill. 2010.

[58] R. Montanini, «Quantitative determination of subsurface defects in a reference specimen made of Plexiglas by means of lock-in and pulse phase infrared thermography », Infrared Physics \& Technology, vol. 53, no 5, p. 363-371, 2010.

[59] F. Galmiche, X. Maldague, S. Valler, et J.-P. Couturier, « Pulsed phased thermography with the wavelet transform », in AIP Conference Proceedings, 2000, vol. 509, p. 609-616.

[60] V. P. Vavilov, S. Marinetti, E. G. Grinzato, et P. G. Bison, « Thermal tomography characterization and pulse-phase thermography of impact damage in CFRP, or why end users are still reluctant about practical use of transient IR thermography », in Proceedings of SPIE, 1998, vol. 3361, p. 275.

[61] C. Ibarra-Castanedo et X. Maldague, "Pulsed phase thermography reviewed », Quantitative Infrared Thermography Journal, vol. 1, no 1, p. 47-70, 2004.

[62] C. I. Castanedo, "Quantitative subsurface defect evaluation by pulsed phase thermography: depth retrieval with the phase », Université Laval, 2005.

[63] F. Weritz, R. Arndt, M. Röllig, C. Maierhofer, et H. Wiggenhauser, « Intestigation of concrete structures with pulse phase thermography », Materials and Structures, vol. 38, no 9, p. 843-849, 2005.

[64] S. Marinetti, Y. A. Plotnikov, W. P. Winfree, et A. Braggiotti, « Pulse phase thermography for defect detection and visualization ", in Nondestructive Evaluation Techniques for Aging Infrastructures \& Manufacturing, 1999, p. 230-238. 